\title{
TINGKAT ESKALASI KONFLIK SUMBER DAYA HUTAN DI DESA REMPEK,KABUPATEN LOMBOK UTARA
}

\author{
Escalation Level of Forest Resources Conflict in Rempek Village of North Lombok
}

\author{
Fitria Mariatun, Sitti Latifah, Budhy Setiawan \\ Program Studi Kehutanan, Universitas Mataram \\ JI Majapahit No 62, Mataram, NTB \\ Email ; slatifa23@yahoo.com
}

\begin{abstract}
The main purpose of this research is to find out the level of escalation of conflict in the village Rempek this time and identify the factors causing the decline in the escalation of conflicts in the village Rempek. The method used in this research is descriptive qualitative by establishing key informant derived from (1) villagers Rempek, (2) Village Government Rempek, (3) The KPHL Rinjani Barat, (4) Team 9, and (5) LSM Samanta, The results showed that in the village of Rempek there are 4 types of conflict is the conflict between (1) BPN NTB with the Forest Service the province, the Department of Agriculture, Plantation, Forestry, Maritime Affairs and Fisheries North Lombok, KPHL Rinjani Barat, (2) the Provincial Forestry Office NTB, the Department of Agriculture, Plantation, Forestry, Maritime Affairs and Fisheries North Lombok, KPHL Rinjani West Village community Rempek, (3) Department of Forestry province, the Department of Agriculture, Plantation, Forestry, Maritime Affairs and Fisheries North Lombok, KPHL Rinjani West Employers local wood (sawmill owners) and (4) the Village Community Rempek with local timber businessmen. This study focuses on the conflict between the regional government with society. Where, based on the results of the analysis show that the conflict in the village eskalsi Rempek has decreased from a high escalation into escalation was caused by several factors: a). Social factors which the public will get legality legally in managing forests through forestry partnership program, b). Economic factors where people's income will increase because the public has an opportunity to utilize timber forest products legally, c). Factors presence of facilitators where people get information and understanding through the facilitator, Tim 9 and NGO Samanta did intensive socialization.
\end{abstract}

Keywords: Escalation Level, Conflicts, Rempek.

\begin{abstract}
Abstrak
Tujuan utama penelitian ini, yaitu untuk mengetahui tingkat eskalasi konflik di Desa Rempek saat ini dan mengidentifikasi faktor-faktor penyebab menurunnya eskalasi konflik di Desa Rempek. Metode yang digunakan dalam penelitian ini yaitu deskriptif kualitatif dengan menetapkan key informan yang berasal dari: (1) masyarakat Desa Rempek, (2) Pemerintah Desa Rempek, (3) Pihak KPHL Rinjani Barat, (4) Tim 9 dan (5) LSM Samanta. Hasil penelitian menunjukkan bahwa di Desa Rempek terdapat 4 jenis konflik yaitu konflik antara (1) BPN Provinsi NTB dengan Dinas Kehutanan Provinsi NTB,
\end{abstract}


Dinas Pertanian, Perkebunan, Kehutanan, Kelautan dan Perikanan Kabupaten Lombok Utara, KPHL Rinjani Barat, (2) Dinas Kehutanan Provinsi NTB, Dinas Pertanian, Perkebunan, Kehutanan, Kelautan dan Perikanan Kabupaten Lombok Utara, KPHL Rinjani Barat dengan masyarakat Desa Rempek, (3) Dinas Kehutanan Provinsi NTB, Dinas Pertanian, Perkebunan, Kehutanan, Kelautan dan Perikanan Kabupaten Lombok Utara, KPHL Rinjani Barat dengan Pengusaha kayu lokal (pemilik sawmill) dan (4) Masyarakat Desa Rempek dengan Pengusaha kayu lokal. Penelitian ini berfokus pada konflik antara Pemerintah Daerah dengan masyarakat. Dimana, berdasarkan hasil analisis diketahui bahwa eskalasi konflik di Desa Rempek mengalami penurunan dari eskalasi tinggi menjadi eskalasi sedang yang disebabkan oleh beberapa faktor yaitu: a). Faktor sosial dimana masyarakat akan mendapatkan legalitas secara hukum dalam mengelola kawasan hutan melalui program kemitraan Kehutanan, b). Faktor ekonomi dimana pendapatan masyarakat akan meningkat karena masyarakat berpeluang untuk memanfaatkan hasil hutan kayu secara legal, c). Faktor kehadiran fasilitator dimana masyarakat mendapatkan informasi dan pemahaman melalui fasilitator yaitu Tim 9 dan LSM Samanta yang melakukan sosialisasi secara intensif.

Kata kunci: Tingkat Eskalasi, Konflik, Rempek.

\section{Pendahuluan}

Luas kawasan hutan Provinsi Nusa Tenggara Barat seluas 1.071.722.83 Ha yang terbagi dalam hutan produksi, hutan konservasi dan hutan lindung. Dengan luasan hutan yang mencapai $51,39 \%$ dari luas daratan provinsi NTB sejalan dengan meningkatnya kepentingan-kepentingan dari para pihak terhadap kawasan hutan. Seiring dengan peningkatan kepentingan dan kebutuhan yang berbeda-beda terhadap kawasan hutan, sehingga dapat memicu terjadinya konflik sumber daya hutan. Dari luas kawasan hutan di NTB sekitar 80.147,22 Ha mengalami konflik tenurial. Salah satu konflik tenurial di Provinsi Nusa Tenggara Barat terjadi di Desa Rempek Kabupaten Lombok Utara.

Konflik tenurial yang terjadi di Desa Rempek merupakan konflik sumber daya hutan antara Pemerintah Daerah (Dinas Kehutanan Provinsi NTB, Dinas Pertanian, Perkebunan, Kehutanan, Kelautan dan Perikanan Kabupaten Lombok Utara, KPHL Rinjani Barat) dengan masyarakat Desa Rempek. Hal tersebut disebabkan karena masyarakat Desa Rempek menolak batas hutan yang ditetapkan Pemerintah dan mengklaim batas hutan zaman Belanda bukan sebagai kawasan hutan. Konflik diperparah dengan di terbitkannya sertifikat kawasan hutan oleh BPN Provinsi Nusa Tenggara Barat melalui PRONA tahun 1984 sebanyak 86 Persil. Konflik di Desa Rempek ini sudah terjadi selama 30 tahun lebih dan berada pada tingkat eskalasi tinggi karena masyarakat tidak mau menerima segala macam program yang ditawarkan oleh Pemerintah khususnya pihak Kehutanan sampai tahun 2010.

KPHL Rinjani Barat selaku pengelola hutan tingkat tapak melakukan upaya-upaya dalam menyelesaikan konflik tenurial yang terjadi di Desa Rempek melalui programprogram yang ditawarkan kepada masyarakat Desa Rempek dengan kerja sama berbagai pihak. Upaya yang di lakuakan pihak KPHL Rinjani Barat selama 5 tahun terakhir menunjukkan kemajuan yang sangat positif, dimana masyarakat menerima program yang ditawarkan oleh Pemerintah yaitu KPHL Rinjani Barat. Tujuan dari penelitian ini yaitu: (1) mengetahui tingkat eskalasi konflik di Desa Rempek saat ini dan (2) mengidentifikasi faktor-faktor penyebab turunnya eskalasi konflik di Desa Rempek. 


\section{Metode}

Metode yang digunakan dalam penelitian ini yaitu deskriptif kualitatif dengan mengumpulkan data-data tertulis atau ucapan lisan dari informan dan subjek penelitian. Dilihat dari jenis masalah yang akan diteliti penelitian ini menggunakan strategi penelitian studi kasus yaitu penelitian tentang status subjek penelitian yang spesifik dari keseluruhan personalitas (Maxfield,1930 dalam Nazir 2011). Tujuan dari studi kasus untuk memberikan gambaran secara rinci terhadap latar belakang, sifat, karakter yang khas dari kasus yang kemudian dari sifat khas akan dijadikan suatu hal yang bersifat umum (Nazir, 2011). Untuk memperoleh informasi peneliti mempergunakan key informan yang dipilih secara sengaja, key informan dipilih berdasarkan keterlibatan secara langsung maupun tidak langsung terhadap konflik yang terjadi di Desa Rempek. Key informan yang dipilih peneliti berasal dari: (1) masyarakat Desa Rempek, (2) Pemerintah Desa Rempek, (3) Pihak KPHL Rinjani Barat, (4) Tim 9 dan (5) LSM Samanta.

\section{Hasil dan Pembahasan}

\section{Gambaran Umum Wilayah Penelitian}

Rempek adalah sebuah desa yang secara administratif berada di wilayah Kecamatan Gangga, Kabupaten Lombok Utara, Provinsi Nusa Tenggara Barat dengan luas wilayah 3.085,5 hektar (ha), dengan ketinggian 350-500 meter di atas permukaan laut. Desa Rempek berjarak $13 \mathrm{Km}$ dari Gondang yang merupakan ibu kota kecamatan Gangga dapat ditempuh dengan waktu setengah jam dan berjarak $19 \mathrm{Km}$ dari Tanjung yang merupakan ibu kota Kabupaten Lombok Utara.

\section{Sejarah Tingkat Eskalasi Konflik Antara Pemerintah Daerah Dengan Masyarakat}

Konfik tenurial yang terjadi di Desa Rempek sudah berlangsung lebih dari 30 tahun dengan tingkat eskalasi tinggi. Konflik tenurial ini melibatkan beberapa pihak baik secara langsung maupun tidak langsung yaitu Dinas Kehutanan Provinsi NTB, Dinas Pertanian, Perkebunan, Kehutanan, Kelautan dan Perikanan Kabupaten Lombok Utara, KPHL Rinjani Barat, Masyarakat Desa Rempek, Pengusaha kayu lokal (Pemilik Sawmil) dan Badan Pertanahan Nasional Provinsi NTB, Pemerintah Desa Rempek, Tim 9 dan LSM Samanta. Berdasarkan hasil penelitian menunjukkan bahwa tingkat eskalasi konflik yang terjadi di Desa Rempek sudah mengalami penurunan dari tingkat eskalasi terbuka menjadi tingkat tertutup menurut kriteria Kemenhut (2012), sedangkan menurut kriteria KPHL Rinjani Barat tingkat eskalasi konflik sudah mengalami penurunan dari tingkat eskalasi tinggi menjadi tingkat eskalasi sedang. Berdasarkan hasil wawancara yang dilakukan tahun 2015 kepada 14 key informan yang terdiri dari masyarakat yang berkonflik 6 orang, pihak KPHL Rinjani Barat 2 orang, tim 9 selaku mandor di lapangan 4 orang, Pemerintah Desa yaitu Kepala Desa Rempek 1 orang dan pihak LSM Samanta selaku fasilitasi 1 orang. Dari keseluruhan jumlah key informan sebanyak 2 orang atau sekitar 14,3\% dari pihak masyarakat masih menuntut sertifikat dan tidak mau ikut masuk program. Sedangkan, sisa dari key informan sebanyak 12 orang atau sekitar 85,7\% dari keseluruhan jenis key informan menyatakan konflik di Desa Rempek mengalami

penurunan. Sejarah kejadian dan tingkat eskalasi konflik yang terjadi di Desa Rempek dapat diihat pada gambar 1 dan 2 dibawah ini: 


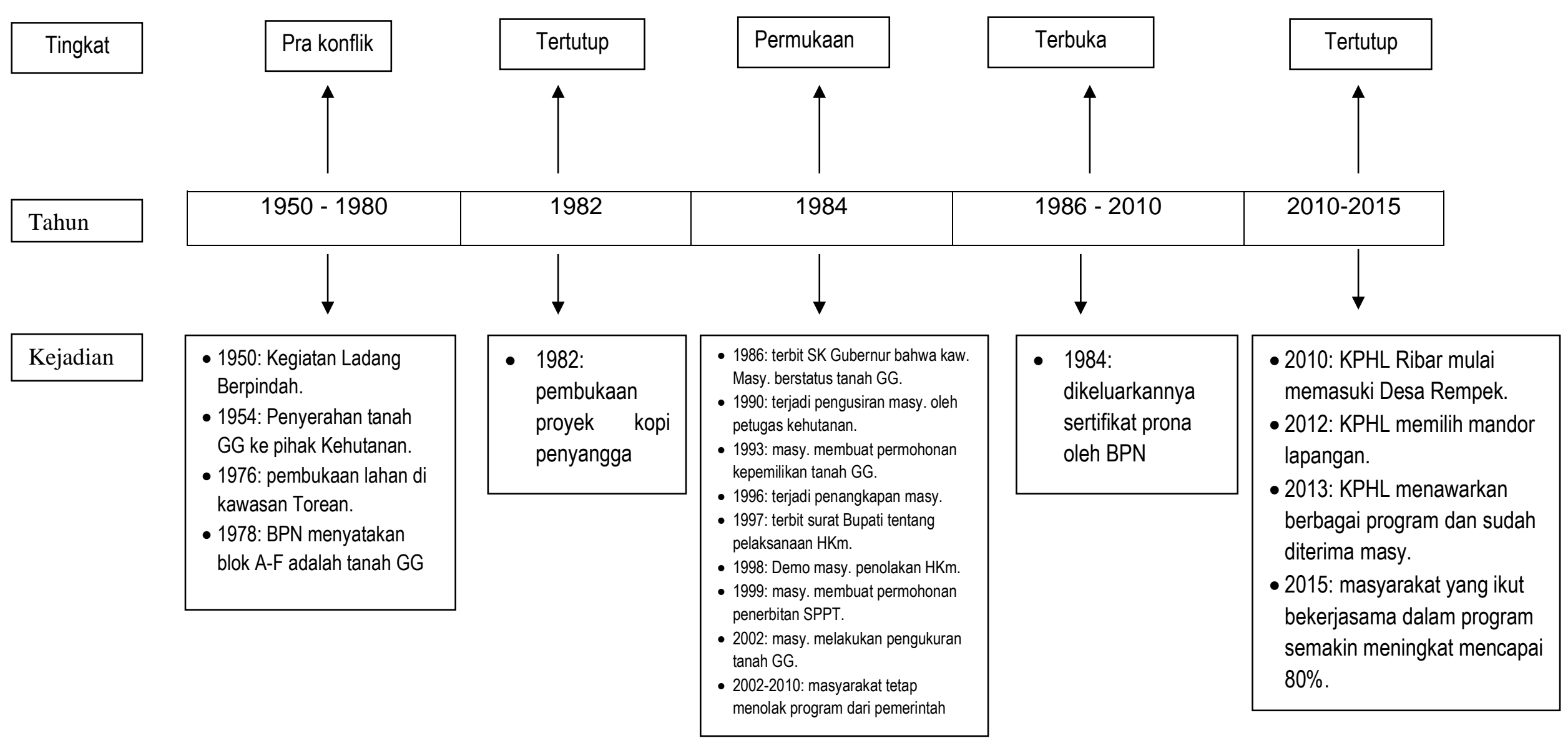

Gambar 1 Kejadian Dan Tingkat Konflik Menurut Kemenhut (2012)

Figure 1 Genesis and Conflict Level According to Kemenhut (2012) 


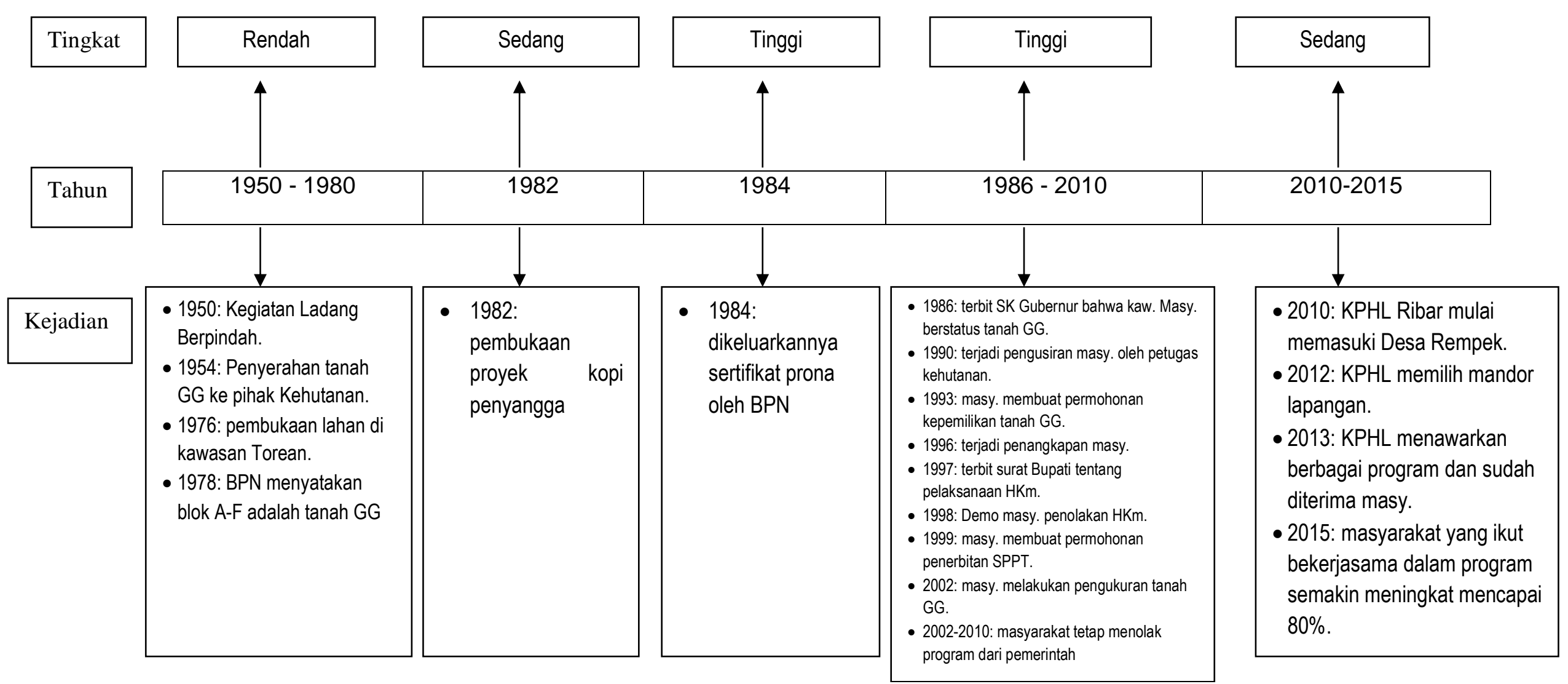

Gambar 2. Kejadian Dan Tingkat Konflik Menurut KPHL Dalam Handoko (2014)

Figure 2. Genesis and Conflict Level According to KPHL In Handoko (2014) 
Hal ini menunjukkan bahwa konflik yang terjadi di Desa Rempek berada dalam eskalasi tinggi sebelum tahun 2010 karena adanya sertifikat prona dan masyarakat $100 \%$ tidak mau menerima program dari Pemerintah Kehutanan. Namun setelah tahun 2010 sampai 2015 masyarakat menerima program KPHL Rinjani Barat mencapai 80\%.

\section{Faktor-faktor yang Mempengaruhi Tingkat Eskalasi Konflik}

Berikut ini adalah faktor-faktor yang mempengaruhi penurunan eskalasi konflik tenurial di Desa Rempek.

1. Faktor sosial

a. Status hukum lahan hutan yang selama ini dikelola oleh masyarakat tanpa ijin akan mendapatkan legalitas secara hukum dalam mengelola kawasan hutan melalui program kemitraan Kehutanan yang diberikan KPHL Rinjani Barat kepada masyarakat akan merubah kebiasaan masyarakat yang memanfaatkan hasil hutan baik kayu maupun non kayu secara ilegal akan mendapatkan surat ijin mengelola yang dapat digunakan untuk melegalkan hasil hutan kayu maupun non kayu sehingga masyarakat tidak dianggap sebagai pelaku penggarap ilegal.

b. Tingkat kesadaran masyarakat di Desa Rempek seiring dengan gencarnya dilakukan sosialisasi secara rutin oleh mandor lapangan yaitu tim 9 menyebabkan masyarakat banyak mendapat informasi tentang hutan maupun pengelolaan hutan itu sendiri, informasi yang diproleh masyarakat mengubah pola pikir masyarakat yang awalnya tidak mau masuk program apapun yang ditawarkan pemerintah sekarang sudah mulai masuk program. Dari tahun 2012-2015 masyarakat yang masuk program sudah mencapai $80 \%$. Melihat dari partisipasi masyarakat yang setiap tahunnya meningkat untuk ikut program menandakan bahwa tingkat kepercayaan masyarakat sudah meningkat terhadap Pemerintah khususnya pihak Kehutanan. Selain itu keinginan kerjasama masyarakat dengan KPHL Rinjani Barat semakin meningkat.

2. Faktor ekonomi

a. Ketergantungan masyarakat terhadap kawasan hutan tidak dapat terelakkan, karena masyarakat dalam memenuhi kebutuhan hidup sehari-hari sangat bergantung pada hasil hutan. Sehingga dengan mengikuti program masyarakat legalitas dalam menjual hasil hutan khususnya hasil hutan kayu.

b. Keinginan masyarakat untuk meningkatkan kesejahteraan dilihat dari masyarakat mengikuti program kemitraan dari Pemerintah. Masyarakat yang ikut program Kemitraan akan langsung menjadi anggota Koperasi yang dimana hasil hutan baik kayu maupun bukan kayu dijual ke koperasi dan sebagian dari hasil penjualan disimpan sebagai tabungan masyarakat di koperasi. Pembagian hasil yang disepakati dalam kemitraan ini tergantung dari jenis yang dihasilkan, untuk jenis kayu (HHK) pembagian hasil yang disepakati adalah 25\% untuk KPHL (Negara) dan 75\% Koperasi sedangkan dari HHBK adalah 10\% untuk pihak KPHL Rinjani Barat (Negara) dan 90\% untuk pihak koperasi.

\section{Faktor Kehadiran Fasilitator}

\section{a. $\operatorname{Tim} 9$}

Penurunan eskalasi konflik yang terjadi dalam kurun waktu 3 (tiga)tahun terakhir ini tidak lepas dari peran Tim 9. Tim 9 merupakan mandor di lapangan yang berjumlah 9 orang bekerjasama dengan KPHL Rinjani Barat untuk ikut bersama-sama dalam mengawal 
program, dimana dalam tim 9 ini memiliki tugas untuk mensosialisasikan program dengan pembagian jabatan sesuai dengan bidang masing-masing.

b. LSM Samanta

LSM Yayasan Masyarakat Nusa Tenggara (SAMANTA) merupakan sebuah lembaga nirlaba yang berbentuk yayasan dimana fokus kegiatannya diarahkan pada upaya penggalangan dana dan pelayanan pendanaan alternatif skala kecil (small grant). Peran LSM Samanta ikut berpartisipasi dalam konflik yang terjadi di Desa Rempek sebagai jembatan antara Pemerintah khususnya pihak kehutanan dengan masyarakat agar konflik yang terjadi selama kurang lebih 30 tahun dengan tingkat eskalasi tinggi dapat menurun. Melihat tingkat eskalasi konflik yang tinggi LSM Samanta ikut bekerja sama dalam memberikan informasi dan pemahaman kepada masyarakat, agar masyarakat sadar akan keuntungan mengikuti program Pemerintah.

\section{Kesimpulan}

Berdasarkan hasil penelitian konflik sumber daya hutan di Desa Rempek dapat disimpulkan sebagai berikut:

1. Selama 5 (lima) tahun terakhir ini terjadi penurunan tingkat eskalasi konflik dari tinggi ke sedang dan dari tingkat konflik terbuka ke tertutup.

2. Faktor-faktor yang mendorong penurunan eskalasi konflik di Desa Rempek yaitu: a). Faktor sosial dimana masyarakat akan mendapatkan legalitas secara hukum dalam mengelola kawasan hutan melalui program kemitraan Kehutanan, b). Faktor ekonomi dimana pendapatan masyarakat akan meningkat karena sudah bisa memanfaatkan HHK secara legal, c). Faktor kehadiran fasilitator dimana masyarakat mendapatkan informasi dan pemahaman melalui mediator yaitu tim 9 dan LSM Samanta yang melakukan sosialisasi secara intensif.

\section{Daftar Pustaka}

Handoko, C. 2014. Kajian Konflik Tenuria Di KPHL Rinjai Barat Studi Kasus Desa Senaru, Santong Dan Rempek. Balai Penelitian Teknologi Hasil Hutan Bukan Kayu. Provinsi Nusa Tenggara Barat.

Kementerian Kehutanan. 2009. SK Menteri Kehutanan Republik Indonesia No. 337/MenhutVII/2009. Tanggal 15 Juni 2009 tentang Penetapan Wilayah KPHL Provinsi Nusa Tenggara Barat.

Kementrian Kehutanan. 2012. Pengelolaan Konflik Sumber Daya Hutan. Pusat Penyuluhan Kehutanan, Kementrian Kehutanan. Jakarta.

Nazir, Mohammad. 2011. Metode Penelitian. Ghalia Indonesia: Bandung

Working Group on Forest-Land Tenure. 2012. Resolusi Konflik di KPHL. Working Group Tenure. Bogor. 